\title{
Review
}

\section{Endothelin: emerging role in diabetic vascular complications}

\author{
R. L. Hopfner, V. Gopalakrishnan
}

Department of Pharmacology and the Cardiovascular Risk Factor Reduction Unit (CRFRU), College of Medicine, University of Saskatchewan, Saskatoon, Canada

\section{Abstract}

Since the discovery of endothelin- 1 as the most potent endothelial-derived vasoconstrictor/mitogenic peptide a decade ago, considerable evidence has implicated this peptide in various cardiovascular disease states, including diabetes mellitus. Plasma and tissue concentrations of endothelin-1 as well as responses to the peptide are changed in various forms of the disease in humans and animals. Endothelin activity is also altered in atherosclerotic and ischaemic disease, nephropathy, retinopathy, erectile dysfunction, and neuropathy, many of the well-known complications of diabetes. Striking new evidence shows that antagonists of the endothelin system might beneficially affect and potentially overcome some of these complications. Despite this, lack of direct proof of causation makes this peptide's role in the disease uncertain. This review examines the current state of thought on the role of endothelin in diabetes and in the complications of the disease as well as the likely roles of altered metabolic variables in modulating endothelin1 concentrations and its activity. It is concluded that although alterations in endothelin-1 release and action are clearly associated with the diabetic state, further studies using inhibitors of the endothelin system are warranted to determine its precise role in the complications of the disease. [Diabetologia (1999) 42: 1383-1394]

Keywords Diabetes mellitus, endothelial derived relaxing factor, endothelin, endothelium, hyperglycaemia, hyperlipidaemia, insulin, cardiovascular complications.

\section{The cardiovascular endothelin system}

The endothelin (ET) family consists of three 21-amino acid peptides designated ET-1, ET-2 and ET-3 $[1,2]$. The biological actions of the ETs are primarily mediated by two distinct, G-protein-coupled receptor subtypes designated $\mathrm{ET}_{\mathrm{A}}$ and $\mathrm{ET}_{\mathrm{B}}$ [2]. Endothelin receptors have a higher affinity for ET-1 and ET-2 than ET-3 and the $\mathrm{ET}_{\mathrm{B}}$ receptor binds all three isoforms with equal affinity. Translation of preproET

Corresponding author: Professor V. Gopalakrishnan, $\mathrm{PhD}, \mathrm{De}-$ partment of Pharmacology, University of Saskatchewan, Saskatoon, SK, Canada, S7N 5E5

Abbreviations: $\left[\mathrm{Ca}^{2+}\right]_{\mathrm{I}}$, Cytosolic free calcium; ET, endothelin; ECE, endothelin converting enzyme; EDRF, endothelial derived relaxing factor; STZ streptozotocin; VSMC, vascular smooth muscle cells.
mRNA generates preproET, which is converted to big ET and finally cleaved by ET converting enzyme (ECE) to facilitate production of biologically active peptide. Endothelin-1 released by vascular endothelial cells exerts an autocrine influence by promoting vasodilatation, subsequent to activation of $\mathrm{ET}_{\mathrm{B}}$ receptors located on endothelial cells. It also exerts a paracrine effect on adjacent vascular smooth muscle cells (VSMC) in evoking vasoconstrictor and mitogenic actions by activation of both $\mathrm{ET}_{\mathrm{A}}$ and $\mathrm{ET}_{\mathrm{B}}$ receptors. The primary target of ET- 1 is the vasculature where it evokes transient vasodilatation mediated by endothelial $\mathrm{ET}_{\mathrm{B}}$ receptors, followed by slow-onset and sustained contraction mediated by $\mathrm{ET}_{\mathrm{A}}$ and $\mathrm{ET}_{\mathrm{B}}$ receptors located on VSMC. The functional response to ET-1 varies throughout different tissues and vascular beds due to differences in distribution and expression of these two receptor subtypes. Endothelin-1 
also induces contraction and increases inotropy in cardiac muscle, regulates salt and water homeostasis through actions in the kidney, stimulates the reninangiotensin and sympathetic nervous systems, contracts pulmonary airway and vascular smooth muscle and induces hypertrophy of vascular, mesangial and cardiac muscle [2]. Importantly, ET-1 is thought to act as a modulator of basal vascular tone.

By maintaining a critical balance between relaxing and contracting factors, the endothelium regulates both vascular tone and growth. Accordingly, the vasoconstrictor and mitogenic actions of ET-1 are opposed by vasodilator and antigrowth factors such as endothelial-derived relaxing factor (EDRF) and prostacyclin secreted by endothelial cells [3]. Key metabolic variables that are changed in diabetes mellitus such as plasma insulin, glucose and lipids are well known to directly regulate the release of ET-1 from endothelial cells as well as modulate receptor expression and responses to the peptide. Furthermore, prolonged and excessive exposure of both endothelial cells and VSMC to the metabolic dysregulation of diabetes mellitus could promote atherosclerotic and other morphological changes that indirectly affect the release and action of ET-1 at various target sites. Accordingly, alterations in ET-1 release and action have been consistently shown in both human diabetes mellitus and animal models of the disease. Morbidity associated with the diabetic state primarily results from pathological changes at the vascular level that logically fit with many of the known actions of ET-1. Thus, considerable interest has been generated towards defining the role of this peptide in the complications of the disease.

\section{Endothelin-1 concentrations in normal and diabetic plasma}

Endothelin-1 comprises the lion's share of circulating ETs, with the other isoforms ranging from undetectable to extremely low in concentration [4]. Moreover, endothelial cells produce almost exclusively ET-1. Thus, for the purposes of this review, 'endothelins' are referred to as simply ET-1. Plasma concentrations of ET-1 range between 1 and 5 pmol rarely exceeding $25 \mathrm{pmol}$, even in pathological states [4]. Whereas this concentration range is inadequate to elicit many of the pharmacological actions of the peptide, the majority of endogenous ET-1 is released from endothelial cells abluminally towards the VSMC [5] and increases (decreases) in ET-1 plasma concentrations are thought to reflect overproduction (underproduction) and spillover (or lack of) of ET-1 from endothelial cells $[6,7]$. Alterations in plasma ET-1 could, however, also reflect changes in renal, receptor or enzyme-mediated clearance of the peptide [2]. Consequently, plasma determinations of ET-1 are limited in that they cannot be regarded as a reliable estimate of synthesized, secreted, or active peptide with regard to effects on VSMC. Moreover, a recent study has questioned the reliability of plasma ET-1 concentrations as determined by RIA [8]. Nonetheless, some vascular beds are highly sensitive to pathophysiological increases in plasma ET-1 and its concentrations are increased in various cardiovascular disease states. Accordingly, several studies have examined the status of ET-1 in the plasma of both human diabetic patients and animal models of the disease.

The status of ET-1 plasma concentrations in Type I (insulin-dependent) diabetes mellitus is controversial. The streptozotocin (STZ) diabetic rat, a widely used model of insulin deficiency characteristic of Type I diabetes, has been shown to have increased plasma ET-1 after 8 weeks [7, 9-11] and attenuated concentrations before 5 weeks [11-14] of exposure to diabetes. Accordingly, the duration of diabetes appears to determine the direction of changes in plasma ET-1 in this animal model [11]. Caution is, however, warranted when interpreting plasma ET-1 concentrations in this model too soon after STZ treatment because actions of STZ itself cannot be ruled out. In patients with Type I diabetes, both increased [15-17] and decreased $[18,19]$ plasma ET-1 has been reported and in patients with Type II (non-insulin-dependent) diabetes mellitus plasma ET-1 has been reported to be both increased $[20,21]$ and unchanged [22, 23]. In addition to duration-dependent effects, interstudy variability in the metabolic state, level of control, presence of established macrovascular complications [16] and methodology for measuring ET-1 [8] are likely to contribute to such discrepancies. Importantly, we have shown that altered plasma ET-1 in diabetes can be restored to normal by restoration of metabolic control [14].

In summary, although it is clear that plasma ET-1 is altered in diabetes, the nature and direction of these changes are not clear. Interstudy variability in study population and assay characteristics probably contribute to discrepancies. Future studies should be directed at determining the relevance and role of altered plasma ET-1 to the complications of the disease. Until the importance of changes in plasma ET1 concentrations is more adequately defined, local and tissue ET-1 concentrations would provide a more relevant measure of pathological changes in ET.

\section{In vitro vascular reactivity studies}

Most ex vivo studies examining vascular responsiveness to vasoactive stimuli (including ET-1) in models of diabetes use the aorta as the prototype vessel. Endothelin-1 causes a potent, sustained contraction of this conduit vessel mediated primarily by $\mathrm{ET}_{\mathrm{A}}$ recep- 
tors present on VSMC. Attenuated vasoconstrictor responses to ET-1 (but not other agonists) are present in aorta from STZ rats as early as 2 weeks after induction of diabetes $[9,10,24]$. Such selectively attenuated responses have been attributed to ET receptor down regulation resulting from either protein kinase C activation or increased ET-1 production [25-27]. On the contrary, we and others have shown increased vasoconstrictor responses to ET-1 and other agonists in vascular tissue from STZ rats as early as 2 weeks after induction of diabetes [11, 14, 28, 29]. Such nonspecific increases in vasoconstriction might be attributed to modification of contraction resulting from either altered $\mathrm{Ca}^{2+}$ channel expression and action [28] or protein kinase $\mathrm{C}$ activation [29]. Whatever the cause, this abnormality can be corrected by restoration of metabolic control [14]. Moreover, we have also shown that the trend towards exaggerated responses to ET-1 reverses and actually becomes slightly attenuated after long-term exposure to diabetes [11]. This occurs in conjunction with the development of endothelial dysfunction and increased plasma lipid concentrations. These data suggest that attenuated responses to ET-1 result from pathological changes occurring only after long-term exposure to diabetes. Thus, similar to ET-1 plasma concentrations, aortic reactivity to ET-1 is at least partly dependent on the pre-existing duration of diabetes.

We have also shown exaggerated ET-1 evokes vasoconstriction in aorta from hyperinsulinaemic/insulin resistant obese Zucker rats [30]. Exaggerated responses in this model, however, are non-specific, because similar results were seen with other agonists $[31,32]$. This abnormality has been attributed to alterations in $\mathrm{Ca}^{2+}$ channel activity in VSMC [31] and is restored by metabolic control [32].

Although it is clear that altered vascular reactivity to ET-1 exists in models of diabetes, there are several limitations to existing studies. Firstly, there is minimal evidence examining vascular responses to ET-1 in diabetes in vascular beds other than aorta. As physiological responses to ET-1 vary amongst different vascular beds, there might be relevant tissue specific changes in reactivity to ET-1 in diabetes. Secondly, there is a high degree of interstudy variability in the methodology used to measure vasoconstriction. Although isometric tension methodology is the most popular method for measuring reactivity, variability in bathing medium, method of expressing reactivity and differing baseline tension applied by different laboratories make interstudy comparisons difficult. Finally, the physiological relevance of changes in aortic reactivity is questionable. The aorta is a conduit vessel thought to contribute little to peripheral resistance. Perfused arterial bed preparations have been developed which are thought to more adequately represent changes in vascular resistance [33]. Consequently, we have recently shown that although aorta from the obese
Zucker rat has exaggerated vasoconstrictor responses to ET-1, mesenteric perfusion responses to the peptide remain unchanged [34]. We [35] and others [10] have, however, also shown that the perfused mesenteric arterial bed of STZ rats has selectively attenuated vasoconstrictor responses to ET-1.

In summary, limited in vitro vascular reactivity studies suggest that alterations in responsiveness to ET-1 exist in both conduit and resistance arteries in models of diabetes. There appears to be some degree of selectivity to these changes indicating that diabetes might affect specifically ET receptors or ET-1 signalling pathways. Some of the differences in responsiveness to ET- 1 in diabetes might be related to changes in the relative proportions of $\mathrm{ET}_{\mathrm{A}}$ and $\mathrm{ET}_{\mathrm{B}}$ receptors. Unfortunately, few studies have examined changes in receptors or receptor subtypes for ET-1 in vascular tissues from diabetic animals. Indeed, the vascular effects of endogenous ET-1 could change in patients with diabetes if there are changes in number or function of $\mathrm{ET}_{\mathrm{A}}$ and $\mathrm{ET}_{\mathrm{B}}$ receptors in certain vascular beds. Furthermore, responses to ET-1 need to be more closely examined in other vascular beds and in smaller vessels where changes in ET-1 reactivity might be more relevant to diabetic pathology.

\section{In vivo haemodynamic studies}

The in vivo response to ET-1 varies in different vascular beds depending on expression and density of vasodilator $\mathrm{ET}_{\mathrm{B}}$ and vasoconstrictor $\mathrm{ET}_{\mathrm{A}}$ and $\mathrm{ET}_{\mathrm{B}}$ receptors. The integrated haemodynamic response to ET-1 consists of a transient drop in blood pressure followed by a slow and sustained increase in blood pressure [1]. The systemic depressor response to ET1 results from vasodilation in the hindquarter and carotid vascular beds, although the renal and mesenteric vascular beds are constricted [36]. During the pressor phase, vasoconstriction predominates in all four vascular beds resulting in an increase in total peripheral resistance. Although cutaneous, splanchic, coronary, pulmonary and renal vascular beds are all potently contracted by systemically administered given ET-1, the latter three are most sensitive to the vasoconstrictor effects of ET-1 [2]. Moreover, studies with ET antagonists indicate that endogenously generated ET-1 acts as a basal regulator of blood pressure in healthy humans [37].

Few studies have assessed haemodynamic responses to ET-1 in vivo in diabetic states. One study showed that renal and mesenteric vasoconstrictor responses to ET-1 were exaggerated in STZ rats whereas initial hindquarter vasodilator responses to ET-1 remained unchanged [38]. If similar effects occur in human diabetes, as the renal and mesenteric vasculatures are primary contributors to the pressor response to ET-1, increases in ET-1 reactivity in these 
beds might contribute to increased total peripheral resistance. Furthermore, the renal vasculature is known to be highly sensitive to physiological increases in plasma ET-1 [39]. Other recent studies show impaired pressor responses to ET-1 in vivo in diabetes $[25,40,41]$. Attenuated ET-1 evoked increases in blood pressure [25] and reductions in cutaneous blood flow [40] were observed as early as 2 weeks after induction of diabetes in STZ rats. The only study in human diabetes examining in vivo reactivity to ET-1 showed a lack of sensitivity to the vasoconstrictor effects of locally infused ET-1 in forearms of patients with Type II diabetes [41]. Increases in perfusion to various vascular beds (including skin and forearm) are well known to be one of the earliest haemodynamic changes associated with human diabetes [42]. Thus, it is plausible that resistance to the basal vasoconstrictor actions of ET-1 resulting in enhanced vasodilatation and excess tissue perfusion contributes to these early changes.

In summary, there are too few studies to draw definite conclusions on haemodynamic responses to ET1 in diabetic states. Based on existing evidence, the haemodynamic actions of ET-1 in diabetes appear dependent on the pre-existing duration of diabetes, the status of endothelial function and vascular bed under consideration. Further studies are warranted examining haemodynamic responses to ET-1 in human diabetes. As ET-1 is thought to contribute to basal vascular tone, alterations in ET-1 reactivity might explain some of the haemodynamic alterations of the disease.

\section{Role of ET-1 in the vascular complications of diabetes mellitus.}

Hypertension. Hypertension occurs in diabetic patients at a greater incidence than in the general population and the combination of the two considerably accelerates the atherosclerotic process [43]. Endothelin-1 is well known to promote sustained increases in blood pressure [44] and a recent landmark study has shown that bosentan, a non-selective $\mathrm{ET}_{\mathrm{A}} / \mathrm{ET}_{\mathrm{B}}$ antagonist, lowers blood pressure in patients with essential hypertension [45]. Thus, ET-1 is a plausible candidate mediator in the development of diabetic hypertension. One study showed that plasma ET-1 acts as a marker of hypertension in patients with type I diabetes [17]. However, in Type I diabetes, increased blood pressure usually develops, as a result of nephropathy [46]. In contrast, hypertension precedes renal damage in Type II diabetes, but its cause is not known. Although plasma ET-1 was shown to be increased in Type II diabetes, those with both hypertension and macrovascular disease, but not with hypertension alone, had higher plasma ET-1 than those with uncomplicated Type II diabetes [47, 48]. Thus, based on limited current evidence, it appears unlikely that ET-1 contributes to hypertension in either Type I or Type II diabetes.

Atherosclerosis. Atherosclerotic vascular disease occurs in diabetic patients at a rate much higher than in the general population and macrovascular complications resulting from atherosclerosis are responsible for the greatest number of deaths associated with the disease [46]. Altered endothelial function occurring in diabetic states ultimately leads to smooth muscle proliferation, an integral feature of atherosclerosis [43]. There is considerable evidence supporting a role for ET-1 in the atherosclerotic process. Endothelin-1 production and plasma concentrations are increased in patients with atherosclerosis [6] and atherosclerotic human arteries have up-regulated ET-1 peptide expression [49]. The non-selective $\mathrm{ET}_{\mathrm{A}} / \mathrm{ET}_{\mathrm{B}}$ receptor antagonist, bosentan, prevented neo-intima formation in a rabbit carotid artery model of atherosclerosis [50], and selective $\mathrm{ET}_{\mathrm{A}}$ blockade reduced atheroma formation independent of plasma cholesterol and blood pressure [51]. Later studies confirmed that increased plasma ET-1 is a marker of atherosclerotic macrovascular disease in patients with Type II diabetes [47, 48, 52]. Furthermore, those with the highest ET-1 concentrations had both atherosclerosis and Type II diabetes [52]. Few other studies have examined the link between diabetes, atherosclerosis and ET-1. Nonetheless, the potent anti-proliferative effects of ET antagonists indicate that blockade of the ET system might have profound beneficial effects on atherosclerotic vascular disease in diabetic patients. Such effects might also be beneficial in reducing vascular remodelling, cardiac hypertrophy and renal glomerulosclerosis resulting from diabetes alone or in combination with hypertension.

Neurovascular abnormalities. An early reduction in blood flow to peripheral nerves leading to endoneurial hypoxia contributes to nerve conduction deficits in diabetes [53]. Studies in STZ rats have established a possible role for ET-1 in the aetiology of attenuated endoneurial blood flow in diabetes. Sciatic axons in these rats are selectively susceptible to ischaemia induced by ET-1 due to more intense and prolonged vasoconstriction to the peptide [54]. Moreover, sciatic nerve motor conduction deficits in diabetic rats were corrected by an $\mathrm{ET}_{\mathrm{A}}$ antagonist, in association with increases in sciatic nutritive endoneurial blood flow [55]. Non-selective $\mathrm{ET}_{\mathrm{A}} / \mathrm{ET}_{\mathrm{B}}$ blockade failed, however, to evoke similar actions [56], indicating that the addition of $\mathrm{ET}_{\mathrm{B}}$ blockade might blunt the beneficial effects of $\mathrm{ET}_{\mathrm{A}}$ antagonism. Moreover, the addition of an angiotensin $\mathrm{AT}_{1}$ receptor antagonist to diabetic rats already treated with an $\mathrm{ET}_{\mathrm{A}}$ antagonist conferred synergistic beneficial effects on nerve conduction [57]. Thus, there is considerable evidence that an in- 
creased vasoconstrictive capacity to ET- 1 is present in the neurovasculature of diabetic animals. Moreover, efficacy of ET antagonists shown in such neurovascular abnormalities provides substantial evidence of a contributory role for the peptide in this complication.

Diabetic retinopathy. Abnormal retinal haemodynamics contribute to the development of diabetic retinopathy [58]. Endothelial cells and pericytes, which constitute the retinal microvasculature, act as the main regulators of retinal blood flow. Ocular tissue is a rich source of ET-1 peptide expression, and ET1 has been shown to maintain ocular blood flow in vivo [59]. Accordingly, alterations in ET-1 production and action have been hypothesized to contribute to diabetic retinopathy and other ocular vascular diseases. Several in vitro studies have shown that hyperglycaemia can alter both production and responses to ET-1 in pericytes, the contractile cells of the retinal microcirculation. Exposure to increased concentration of glucose attenuated cellular signalling and functional contraction evoked by ET-1 in rat retinal pericytes $[60,61]$. Later studies showed that increases in retinal circulation time after intravitreal injection of ET-1 and ET-3 were attenuated [62] in STZ rats and that altered retinal blood flow in these rats could be restored to normal by phosphoramidon, an ECE inhibitor [63]. PreproET mRNA was also increased twofold in the retina of diabetic rats compared with normal controls. These results implicate increases in endogenous ET-1 production and resistance to the vasoconstrictor actions of the peptide in retinal blood flow alterations in diabetes. There are few studies assessing the role of ET-1 in diabetic retinopathy in humans. One recent study showed ET-1 concentrations in the vitreous fluid of diabetic patients with proliferative retinopathy are actually decreased compared with non-diabetic control subjects [64]. Moreover, increased plasma ET-1 has been observed in Type II diabetic patients with retinopathy $[65,66]$ but without other end-organ damage related to diabetes [65].

Nephropathy. The kidney is an important site of action for ET-1 [67]. Glomerular EC, mesangial cells, and epithelial cells secrete ET-1. Endothelin-1 constricts renal vessels, contracts mesangial cells, inhibits salt and water reabsorption, enhances glomerular proliferation and stimulates extracellular matrix accumulation. Although basal tone is only modestly maintained by ET-1, pathophysiological concentrations of ET-1 cause profound renal vasoconstriction with little effect on systemic blood pressure [39].

Alterations in urinary [68, 69], total renal [70, 71], glomerular [72] and ureteral [73] ET-1 peptide, mRNA and receptor levels are present in animal models of diabetes. Studies with ET antagonists have also shown a role for this peptide in renal dysfunction in diabetes. Treatment for 24 weeks with the $\mathrm{ET}_{\mathrm{A}}$ re- ceptor antagonist, FR139317, attenuated the fall in creatinine clearance and reduced urinary protein excretion and mRNA expression for extracellular matrix components and growth factors in glomeruli of STZ rats [74]. Another ET $_{\mathrm{A}}$ antagonist, LU135252, decreased raised urinary ET-1 in STZ rats but only had modest effects on albumin excretion [75]. The non-selective $\mathrm{ET}_{\mathrm{A}} / \mathrm{ET}_{\mathrm{B}}$ receptor antagonist, PD142893, restored renal blood flow to normal and reduced urinary protein and albumin excretion in proteinuric STZ rats to a similar extent as the angiotensin converting enzyme inhibitor, enalapril [76]. Once again, there are few studies examining renal ET-1 in humans with diabetes. Raised 24-h urinary ET-1 was present in Type II diabetic patients with albuminuria [77] and increases in circulating ET-1 preceded the microalbuminuric phase of renal damage related to diabetes [78].

In summary, it is clear that alterations in urinary and renal ET-1 content are associated with diabetic nephropathy and this is another complication where ET antagonists have shown protective effects.

Hypoxia and ischaemia Endothelin-1 is a powerful constrictor of the cerebral and coronary vasculature capable of inducing hypoxia and ischaemia. Hypoxia itself promotes ET-1 synthesis in vivo in humans [79], increases ET receptors in cardiac membranes [80], and augments the contractile actions of ET-1 [81]. Consequently, ET-1 has been hypothesized to contribute to ischaemic damage in conditions such as myocardial infarction and stroke. Plasma concentrations of ET-1 are increased in acute myocardial infarction and are predictive of 1-year mortality in humans [82] and ET antagonists have shown beneficial effects in animal models of both ischaemic heart disease and stroke [83]. The hyperglycaemia of diabetes is known to induce a "pseudohypoxic" state that mimics the effects of true hypoxia on vascular and neural function despite normal tissue partial pressure of oxygen [84]. Accordingly, diabetic patients are known to have increased susceptibility to hypoxic and ischaemic injury in myocardial and cerebral vessels $[85,86]$. The link between ET-1, diabetes and ischaemic stroke or heart disease has, however, not yet been investigated. As hypoxia modulates the release and action of ET-1, it is plausible that the diabetic state potentiates these effects contributing to the greater susceptibility to ischaemic damage in diabetic patients.

\section{Metabolic variables influencing ET-1 production and action in diabetes}

From the above evidence, it is clear that the diabetic state is associated with changes in the release and action of ET-1 in nearly all of the target sites affected 


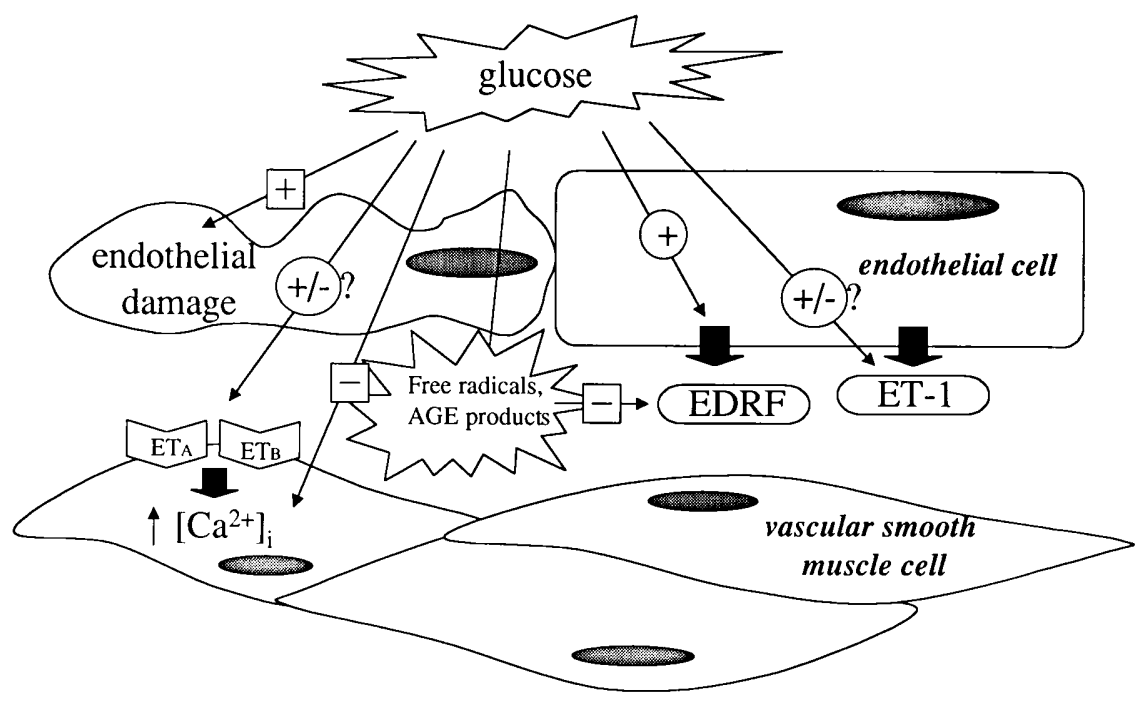

Fig. 1. Effects of high glucose on factors related to ET-1 production and action. Glucose regulates ET-1 peptide and receptor expression as well as responses to the peptide in vitro. The direction of these changes is, however, controversial. High glucose also increases endothelial derived relaxing factor production, through activation of nitric oxide synthase. It also inhibits endothelium derived relaxing factor (EDRF) through endothelial damage and other actions such as advanced glycation end product (AGE) and superoxide radical formation. Such actions could also regulate ET-1 production and action.

by the disease. Much of the evidence presented does not, however, prove a causal role for ET-1 in these complications, and existing human studies are limited to correlations of complications and metabolic control with plasma ET-1 concentrations. Recent evidence that ET antagonists beneficially affect some of these complications in animal models of diabetes provides the most compelling evidence to date that ET1 might be pathogenic in diabetic vascular disease. A key question that remains is what are the factors responsible for the observed changes in ET-1 release and action in diabetes? Due to the plethora of metabolic and cardiovascular abnormalities present in Type I and Type II diabetes and differential effects of the various treatment options on these variables, isolating the causes of changes in ET-1 release and action assumes importance.

Hyperglycaemia. The precise role of high glucose in regulating the release and action of ET-1 is controversial. Hyperglycaemia, the primary metabolic disturbance of diabetes, has been shown to increase [87], decrease [88], and have no effect on $[89,90]$ the release of ET-1 from endothelial cells in culture. Species differences as well as the concentration and duration of incubation of glucose used by these studies probably account for these discrepancies. Studies examining the effect of high glucose on receptors and responses to ET-1 have also yielded somewhat equivocal results. Incubation of cultured aortic smooth muscle cells with high glucose decreased the maximum binding capacity (but not affinity) for ET-1 $[13,91]$. In contrast, pericytes incubated with high glucose showed a statistically non-significant increase in receptors for ET-1 [60]. In both retinal pericytes $[60,61]$ and aortic smooth muscle cells [91], contractile responses to ET-1 are blunted after high glucose incubation, apparently independent of effects on receptor expression. A summary of the effects of high glucose concentration on ET-1 release and action is shown in Figure 1.

Insulin. Type II diabetes is often considered a hyperinsulinaemic state and patients with Type I diabetes on insulin therapy exhibit fluctuations between insulinaemia and glycaemia. Since the seminal discovery that insulin increases gene expression for ET-1 in cultured endothelial cells [92], intense research has focused on explaining the relevance of this effect in pathological states characterized by elevated or fluctuating insulin concentrations. Physiological insulin concentrations are known to increase the release of ET-1 from both human endothelial cells [93] and VSMC [94] in culture and induction of hyperinsulinaemia increases plasma concentrations of ET-1 in humans [93, 95] and animals [13, 14].

Studies have also shown an effect of insulin on changes in tissue reactivity to ET-1, both at the receptor and post receptor level. It was first shown in 1993 that preincubation with high concentrations of insulin increased ET receptor expression in aortic smooth muscle cells in vitro and long-term in vivo insulin delivery to normal and STZ rats increased ET receptors in various tissues [13]. We have recently confirmed these results showing that long-term insulin incubation selectively increases $\mathrm{ET}_{\mathrm{A}}$ receptor expression and cytosolic free calcium $\left(\left[\mathrm{Ca}^{2+}\right]_{\mathrm{i}}\right)$ responses in rat aortic smooth muscle cells [30]. Further- 


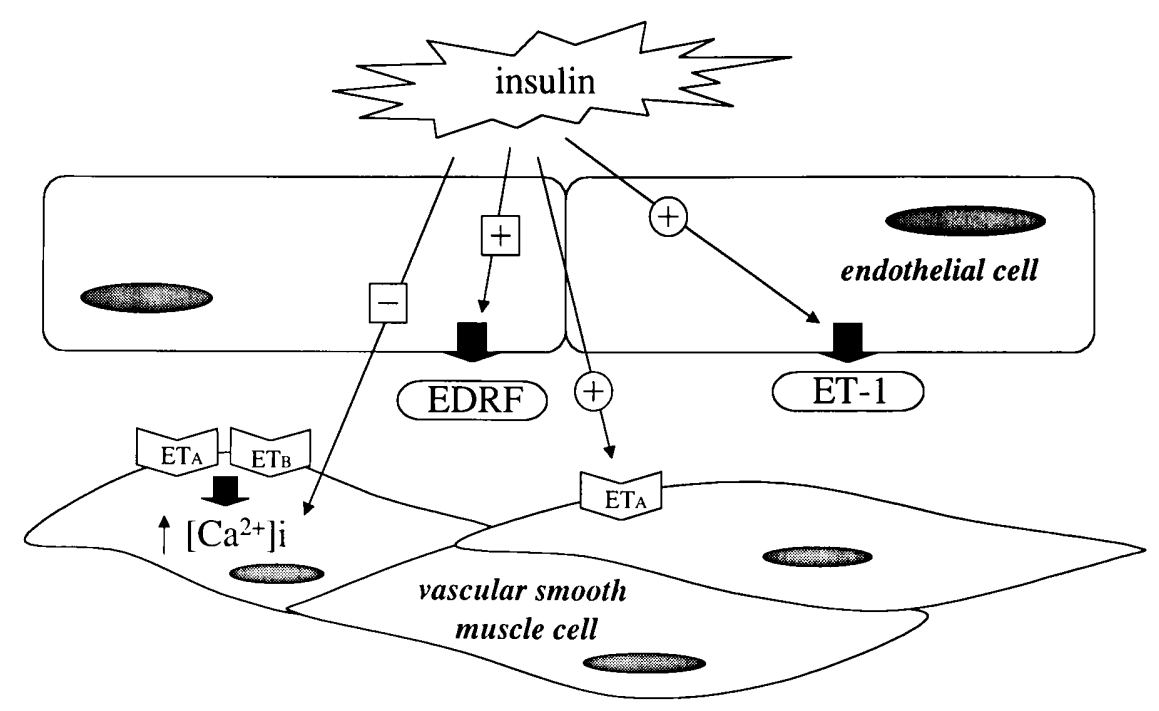

Fig. 2. Effects of insulin on factors related to ET-1 production and action. Insulin increases ET-1 peptide production by gene activation of ET-1. Insulin also selectively up regulates $\mathrm{ET}_{\mathrm{A}}$ receptors on vascular smooth muscle cells after long-term incubation and enhances subsequent $\left[\mathrm{Ca}^{2+}\right]_{\mathrm{i}}$ responses to ET-1. In contrast, short-term incubation of VSMC with insulin attenuates $\left[\mathrm{Ca}^{2+}\right]_{\mathrm{i}}$ responses evoked by ET-1. Insulin also increases EDRF formation by nitric oxide synthase activation

more, $\mathrm{ET}_{\mathrm{A}}$ receptors are increased in vascular tissue from hyperinsulinaemic obese Zucker [30] and fructose hypertensive [96] rats, indicating possible physiological relevance to these findings. In contrast, short-term incubation of VSMC with insulin appears to have a suppressive effect on vascular responses evoked by ET-1 (as well as other agonists). Porcine coronary artery $\left[\mathrm{Ca}^{2+}\right]_{\mathrm{i}}[97]$ and contractile [98] responses to ET-1 were attenuated in the presence of physiological concentrations of insulin through an endothelium-independent mechanism. In endothelium-intact rat aortic rings in the presence of insulin, arterial contraction induced by potassium chloride was, however, exaggerated in a manner dependent on ET-1 [99]. Therefore it appears that the effect of insulin on smooth muscle responsiveness to ET-1 in vitro depends on both the term of exposure to insulin and on the presence or absence of intact endothelium for the release of ET-1.

In conclusion, insulin appears to be a modulator of ET-1 peptide, ET receptors and ET-1 mediated responses - in both in vitro and in vivo settings (Fig. 2). Hyperinsulinaemia itself has been hypothesized to contribute to accelerated vascular disease [46]. Thus, it is plausible that changes in ET-1 activity evoked by insulin could be pathophysiologically relevant. Studies examining the effects of long-term treatment with ET antagonists on vascular pathology in hyperinsulinaemic states would be useful in clarifying the significance of this interaction.
Lipids. Raised plasma lipoproteins are present in both Type I and Type II diabetic patients, particularly in those with poor metabolic control $[46,100]$. Considerable evidence indicates a profound ability of plasma lipoproteins to affect both the release and action of ET-1. Oxidized LDL evokes a concentration and time dependent increase in preproET mRNA expression in porcine and human endothelial cells [101, 102] whereas only high concentrations of native VLDL and LDL have a similar effect [102]. Moreover, raised plasma lipids increase endothelial cell [103], coronary [104] and plasma [95, 104] ET-1 concentrations in vivo. Furthermore, the effect of hyperlipidaemia on plasma ET-1 is synergistic with hyperinsulinaemia in humans [95] and plasma ET-1 is increased in patients with raised plasma lipoproteins even before the development of atherosclerosis [105].

Similar to observations with insulin and glucose, raised lipids are capable of altering tissue responsiveness to ET-1. Hypercholesterolaemic rabbits show exaggerated vascular reactivity to vasoactive peptides, including ET-1, before the development of endothelial dysfunction [106] and pigs fed a high cholesterol diet for 10 weeks have accentuated coronary vasoconstrictor responses to ET-1 [107]. Thus, similar to both insulinaemia and hyperglycaemia, hyperlipidaemia in itself has the capability to regulate plasma concentrations of ET-1 as well as receptors and tissue reactivity to the peptide (Fig. 3 ).

Endothelial dysfunction, EDRF action, and duration of disease. The nature of endothelial dysfunction in diabetes is controversial. Increased EDRF production is thought to occur in early diabetes due to nitric oxide synthase activation mediated by hyperglycaemia [108, 109]. It is, however, also well established that the metabolic dysregulation of diabetes is associated with inhibition of EDRF release and action through a multitude of direct and indirect actions (Fig. 4; [46,109]). Considerable evidence implicates 


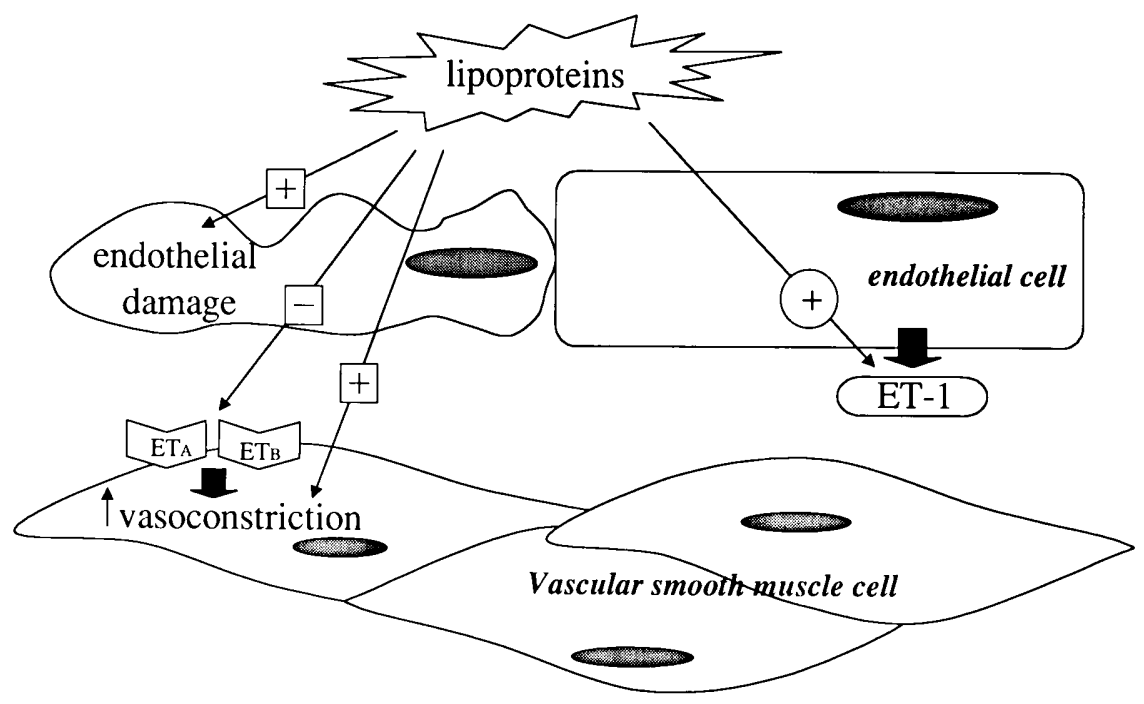

Fig. 3. Effects of plasma lipids on factors related to ET-1 production and action. Oxidized low-density lipoproteins increase ET-1 gene expression and raised lipoproteins in vivo accentuate vascular responses to agonists (including ET-1) before the onset of atherosclerosis. After the onset of atherosclerosis, ET receptors are decreased and ET-1 peptide increased in animal models of the disease. Moreover, endothelial damage resulting from the cascade of atherosclerotic events resulting from dyslipidaemia would be expected to modulate the release and action of ET-1

differences in the duration of exposure to diabetes in determining the nature and direction of these changes. Although hyperglycaemia could activate EDRF production in the short term, as the duration of diabetes progresses, atherosclerotic changes [46] and other events such as advanced glycation end product [110] and superoxide radical formation [111] clearly promote pathological changes in endothelial function leading to suppressed EDRF action. Accordingly, a recent study showed that vasodilatation mediated by EDRF is accentuated in short term STZ rats but becomes paradoxically impaired with increasing duration of diabetes [112]. Moreover, we have recently observed attenuated EDRF-mediated vasodilatation in 14-week, but not 2 week, STZ rats [11].

Alterations in EDRF in diabetes could also appreciably affect ET-1 activity. It is well known that EDRF suppresses ET-1 release [113] and endothelial damage itself is thought to be associated with increased release of ET-1 [6,7,114]. Moreover, ET receptor blockade restored EDRF function in a model of atherosclerosis, suggesting that ET-1 acts to inhibit EDRF in pathological states [51]. Such a link between changes in EDRF and endothelial function and the release and action of ET-1 might have a profound effect on ET-1 activity in diabetes (Fig. 4). Accordingly, as diabetes progresses from diagnosis to end stage, changes in ET-1 release and action would vary in parallel with changes in EDRF and endothelial function. Indeed, we have shown that changes in plasma concentrations of ET-1 and vascular responses to ET-1 in STZ rats are duration-dependent and occur in parallel with changes in endothelial function [11]. Further studies are required to determine if this relation holds true in humans and if such changes are relevant to the pathophysiology of diabetic vascular complications.

Metabolic variables - summary. It is clear that many of the well-known metabolic abnormalities encountered in diabetes contribute individually and synergistically to alterations in the release and action of ET-1. Further studies examining how ET blockers affect the sequelae of each of these abnormalities are required to determine the physiological relevance of these actions. Furthermore, examining how these factors interact in vivo and how current treatment options for the metabolic dysregulation of diabetes act to modulate ET-1 activity in diabetic humans assumes importance.

\section{Conclusion}

The diabetic state is associated with a multitude of metabolic abnormalities capable of directly and indirectly contributing to endothelial and VSM dysfunction and consequently affecting ET-1 release and action. The important role of ET-1 as a modulator of vascular tone and growth indicate that such changes might have important pathophysiological consequences in the development of diabetic vascular complications. To date, research has focused to a large extent on changes in vascular reactivity and circulating plasma concentrations of ET-1 in diabetes. Although easy to study, these variables give few clues as to its role in the disease. Antagonists of the ET system are rapidly progressing to the clinic for the treatment of 


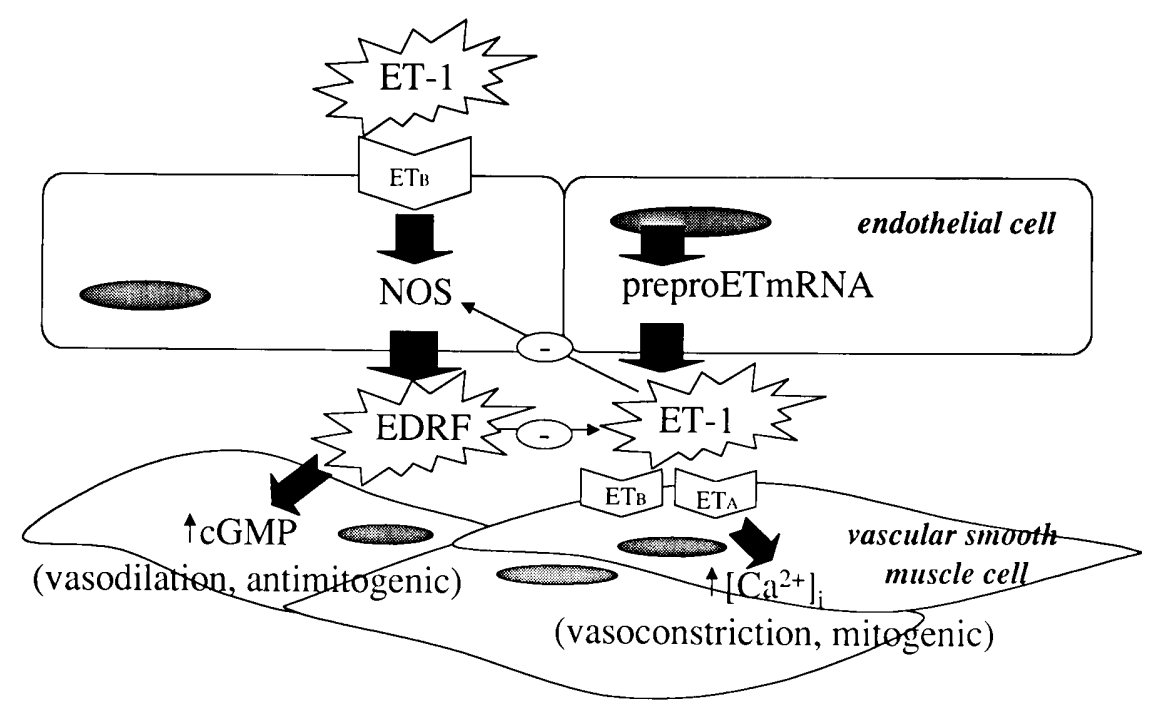

Fig. 4. Interrelation between ET-1 and EDRF. Endothelin-1 is the main vasoconstrictor/mitogenic mediator released by the vascular endothelium whereas EDRF modulates vasodilation/ anti-growth effects. At the gene level EDRF inhibits ET-1. Conversely, ET-1 might inhibit EDRF in pathological conditions. Thus, factors that regulate one system can be expected to affect the other. The metabolic dysregulation of diabetes has profound effects on both EDRF and ET-1 release and action. Such interdependence might be evident in early and late stage diabetes where changes in endothelial and EDRF function appear to coincide with changes in ET-1 release and action

cardiovascular conditions including congestive heart failure, cerebrovascular ischaemia and pulmonary hypertension. Groundbreaking recent studies in diabetic animal models indicate that blockers of the ET system might also beneficially affect and even reduce some of the complications of diabetes such as nephropathy and neuropathy. It is imperative that future studies be directed towards examining the effects of ET antagonists or ECE inhibitors or both on these and other complications in models of diabetes. Such studies will determine whether there is a definitive role for ET-1 in the pathogenesis of diabetic vascular disease.

Acknowledgements. The authors are grateful to the Medical Research Council of Canada for providing grant-in-aid (grant no. MT-14877 to V. Gopalakrishnan) and Doctoral Research Scholarship (to R.L. Hopfner) support for the work carried out in our laboratory cited in this review.

\section{References}

1. Yanagisawa M, Kurihara H, Kimura S et al. (1998) A novel potent vasoconstrictor peptide produced by vascular endothelial cells. Nature 332: 411-415

2. Haynes WG, Webb DJ (1998) Endothelin as a regulator of cardiovascular function in health and disease. J Hypertens 16: 1081-1098
3. Vane JR, Angaard EA, Botting RM (1990) Regulatory functions of the vascular endothelium. N Eng J Med 323: 27-36

4. Frelin C, Guedin D (1994) Why are circulating concentrations of endothelin-1 so low? Cardiovasc Res 28: $1613-1622$

5. Wagner OF, Christ G, Woita J et al. (1992) Polar secretion of endothelin-1 by cultured endothelial cells. J Biol Chem 267: $16066-16068$

6. Lerman A, Edward BS, Hallet JW, Heublein DM, Sandberg SM, Burnett JC (1991) Circulating and tissue endothelin immunoreactivity in advanced atherosclerosis. $\mathrm{N}$ Eng J Med 325: 997-1001

7. Takeda Y, Miyamori I, Yoneda T, Takeda R (1991) Production of endothelin-1 from the mesenteric arteries of streptozotocin induced diabetic rats. Life Sci 48: 2553 2556

8. Baumgartner-Parzer SM, Nowotny P, Wagner O, Waldhäusl W (1998) Determination of plasma ET-1 by RIArisks and limitations. Horm Metab Res 30: 633-635

9. Tada H, Muramatsu I, Nakai T, Kigoshi S, Miyabo S (1994) Effects of chronic diabetes on the responsiveness to endothelin- 1 and other agents of rat atria and thoracic aorta. Gen Pharmacol 25: 1221 - 1228

10. Makino A, Kamata K (1998) Elevated plasma endothelin1 level in streptozotocin-induced diabetic rats and responsiveness of the mesenteric arterial bed to endothelin-1. Br J Pharmacol 123: 1065-1072

11. Hopfner RL, McNeill JR, Gopalakrishnan V (1999) Endothelin plasma levels and endothelin-1 evoked vascular responses at different temporal stages of diabetes in streptozotocin diabetic rats. Eur J Pharmacol 374: 221-227

12. Takahashi K, Suda K, Lam HC, Ghatei MA, Bloom SR (1991) Endothelin like immunoreactivity in rat models of diabetes mellitus. J Endocrinol 130: 123-127

13. Frank HJ, Levin ER, Hu RM, Pedram A (1993) Insulin stimulates endothelin binding and action on cultured vascular smooth muscle cells. Endocrinology 133: 1092-1097

14. Hopfner RL, Misurski D, Wilson TW, McNeill JR, Gopalakrishnan V (1998) Insulin and vanadate restore decreased plasma endothelin concentrations and exaggerated vascular responses to normal in the streptozotocin diabetic rat. Diabetologia 41: 1233-1240

15. Takahashi K, Ghatei MA, Lam HC, O'Hallaran DJ, Bloom SR (1990) Elevated plasma endothelin in patients with diabetes mellitus. Diabetologia 33: 306-310 
16. Collier A, Leach JP, McClellan A, Jardine A, Morton JJ, Small M (1992) Plasma endothelin like immunoreactivity levels in IDDM patients with microalbuminuria. Diabetes Care 15: 1038-1040

17. Haak T, Jungmann E, Felber A, Hillmann U, Usadel KH (1992) Increased plasma levels of endothelin in diabetic patients with hypertension. Am J Hypertens 5: 161-166

18. Smulders RA, Stehouwer CD, Olthof CG et al. (1994) Plasma endothelin levels and vascular effects of intravenous L-arginine infusion in subjects with uncomplicated insulin-dependent diabetes mellitus. Clin Sci (Colch) 87: $37-43$

19. Malamitsi-Puchner A, Economou E, Katsouyanni K, Karachaliou F, Delis D, Bartsocas CS (1996) Endothelin 1-21 plasma concentrations in children and adolescents with insulin dependent diabetes mellitus. J Paediatr Endocrinol Metab 9: 463-468

20. Donatelli M, Colletti I, Bucalo ML, Russo V, Verga S (1994) Plasma endothelin levels in NIDDM patients with macroangiopathy. Diabetes Res 25: 159-164

21. Morise T, Takeuchi Y, Kawano M, Koni I, Takeda R (1995) Increased plasma levels of immunoreactive endothelin and von Willebrand factor in NIDDM patients. Diabetes Care 18: 87-89

22. Kanno K, Hirata Y, Shichiri M, Marumo F (1991) Plasma endothelin-1 levels in patients with diabetes mellitus with or withour vascular complication. J Cardiovasc Pharmacol 17[Suppl 7]:S475-S476

23. Guvener N, Aytemir K, Aksoyek S, Gedik O (1997) Plasma endothelin-1 levels in non-insulin dependent diabetes mellitus patients with macrovascular disease. Coron Artery Dis 8: 253-258

24. Fulton DJ, Hodgson WC, Sikorski BW, King RG (1991) Attenuated responses to endothelin- $1, \mathrm{KCl}$, and $\mathrm{CaCl}_{2}$, but not noradrenaline of aorta of from rats with streptozotocin induced diabetes mellitus. Br J Pharmacol 104: 928-932

25. Guillon JM, Thiry C, Roach AG, Cavero I (1998) Preferential reduction in vascular responses to endothelin- 1 in rats with streptozotocin induced diabetes. J Cardiovasc Pharmacol 31[Suppl 1] :S133-S137

26. Awazu M, Parker RE, Harvie BR, Ichikawa I, Kon V (1991) Down regulation of endothelin-1 receptors by protein kinase $\mathrm{C}$ in streptozotocin diabetic rats. J Cardiovasc Pharmacol 17[Suppl 7]:S500 - S502

27. Clozel M, Loffler BM, Breu V, Hilfiger L, Maire JP, Butscha B (1993) Downregulation of endothelin receptors by autocrine production of endothelin-1. Am J Physiol 265:C188-C192

28. White RE, Carrier GO (1990) Vascular contraction induced by activation of membrane calcium ion channels in streptozotocin diabetes. J Pharmacol Exp Ther 253: 1057-1062

29. Abebe W, Macleod KM (1990) Protein kinase C mediated contractile responses of arteries from diabetic rats. $\mathrm{Br} \mathrm{J}$ Pharmacol 101: 465-471

30. Hopfner RL, Hasnadka RV, McNeill JR, Wilson TW, Gopalakrishnan V (1998) Insulin increases endothelin-1 evoked intracellular free $\mathrm{Ca}^{2+}$ responses by increased $\mathrm{ET}_{\mathrm{A}}$ receptor expression in aortic smooth muscle cells. Diabetes 47: 937-944

31. Zemel B, Sowers JR, Shehin S, Walsh F, Levy J (1990) Impaired calcium metabolism assoiated with hypertension in zucker obese rats. Metabolism 39: 704-708

32. Hopfner RL, McNeill JR, Gopalakrishnan V (1998) Vanadate treatment normalizes exaggerated vascular responses in the obese Zucker rat. Eur J Pharmacol 357: 61-65
33. Christensen KL, Mulvany MJ (1993) Mesenteric arcade arteries contribute substantially to vascular resistance in conscious rats. J Vasc Res 30: 73-79

34. Hopfner RL, Misurski DA, McNeill JR, Gopalakrishnan V (1999) Effect of sodium orthovanadate treatment on cardiovascular function in the hyperinsulinaemic, insulin resistant obese Zucker rat. J Cardiovasc Pharmacol "in press"

35. Misurski DA, Hopfner RL, McNeill JR, Gopalakrishnan V (1999) Perfused mesenteric vascular bed responses in the streptozotocin diabetic rat are dependent on the stage of diabetes: a focus on the vascular endothelium. Proc West Pharmacol Soc 42: 49-51

36. Gardiner SM, Compton AM, Bennett T (1989) Regional haemodynamic effects of endothelin-1 in conscious, unrestrained, Wistar rats. J Cardiovasc Pharmacol 13[Suppl 5]:S202-S204

37. Haynes WG, Gerro CJ, O'Kane KP, Somerville D, Omax CC, Webb DJ (1996) Systemic endothelin receptor blockade decreases peripheral vascular resistance and blood pressure in humans. Circulation 93: 1860-1870

38. Kiff RJ, Gardiner SM, Compton AM, Bennett T (1991) The effects of endothelin-1 and NG-nitro-L-arginine methyl ester on regional haemodynamics in conscious rats with streptozotocin-induced diabetes mellitus. Br J Pharmacol 103: 1321-1326

39. Sorenson SS, Madsen JK, Pedersen EB (1994) Systemic and renal effect of intravenous infusion of endothelin-1 in healthy human volunteers. Am J Physiol 266:F411-F418

40. Lawrence E, Brain SD (1992) Altered microvascular reactivity to endothelin-1, endothelin-1, and NG-nitro-L-arginine methyl ester in streptozotocin induced diabetes mellitus. Br J Pharmacol 106: 1035-1040

41. Nugent AG, McGurk C, Hayes JR, Johnston GD (1996) Impaired vasoconstriction to endothelin-1 in patients with NIDDM. Diabetes 45: 105-107

42. Parving HH, Viberti GC, Keen H, Christiansen JS, Lassen NA (1983) Hemodynamic factors in the genesis of diabetic microangiopathy. Metabolism 32: 943-949

43. Hsueh WA, Anderson PW (1992) Hypertension, the endothelial cell. And the vascular complications of diabetes mellitus. Hypertension 20: 253-263

44. Vierhapper H, Wagner O, Nowotny $P$, Waldhäusl W (1990) Effect of endothelin-1 in man. Circulation 81: $1415-1418$

45. Krum H, Viskoper RJ, Lacourciere Y, Budde M, Charlon V (1998) The effect of an endothelin-receptor antagonist, bosentan, on blood pressure in patients with essential hypertension. Bosentan Hypertension Investigators. N Engl J Med 338: 784-790

46. Epstein M, Sowers JR (1992) Diabetes mellitus and hypertension. Hypertension 19: 403-418

47. Fernandez AC, Patino R, Ibarra J et al. (1995) Endothelin in hypertension and diabetes mellitus. In: Luscher TF (ed) Endothelin in cardiovascular diseases. Springer, Berlin Heidelberg, New York, pp 157-170

48. Perfetto F, Tarquini R, de Leonardis V et al. (1997) Vascular damage and not hypertension per se influences endothelin-1 plasma levels in patients with non insulin dependent diabetes mellitus. Recenti Prog Med 88: 317-320

49. Winkles JA, Alberts GF, Brogi E, Libby P (1993) Endothelin-1 and endothelin receptor mRNA expression in normal and atherosclerotic human arteries. Biochem Biophys Res Commun 191: 1081-1088

50. Marano G, Palazessi S, Bernucci P, Grigioni M, Formigari $\mathrm{R}$, Ballerini L (1998) $\mathrm{ET}_{\mathrm{A}} / \mathrm{ET}_{\mathrm{B}}$ receptor antagonist bosentan inhibits neo-intimal development in collared carotid arteries of rabbits. Life Sci 63:PL259-PL266 
51. Barton M, Haudenschild CC, d'Uscio LV, Shaw S, Munter K, Luscher TF (1998) Endothelin ETA receptor blockade restores NO-mediated endothelial function and inhibits atherosclerosis in apoliprotein E-deficient mice. Proc Natl Acad Sci USA 95: 14367-14372

52. Perfetto F, Tarquini R, Tapparini L, Tarquini B (1998) Influence of non-insulin dependent diabetes mellitus on plasma endothelin-1 levels in patients with advanced atherosclerosis. J Diabetes Complications 12: 187-192

53. Young MJ, Veves A, Walker MG, Boulton AJM (1992) Correlations between nerve function and tissue oxygenation in diabetic patients: further clues to the aetiology of diabetic neuropathy? Diabetologia 35: 1146-1150

54. Zochodne DW, Cheng C, Sun H (1998) Diabetes increases sciatic nerve susceptibility to endothelin induced ischaemia. Diabetes 45: 627-632

55. Cameron NE, Dines KC, Cotter MA (1994) The potential contribution of endothelin-1 to neurovascular abnormalities in streptozotocin diabetic rats. Diabetologia 37: 1209-1215

56. Stevens EJ, Tomlinson DR (1995) Effects of endothelin receptor antagonism with bosentan on peripheral nerve function in experimental diabetes. Br J Pharmacol 115: 373-379

57. Cameron NE, Cotter MA (1996) Effects of a nonpeptide endothelin-1 ETA antagonist on neurovascular function in diabetic rats: interaction with the renin-angiotensin system. J Pharmacol Exp Ther 278: 1262-1268

58. Kohner EM, Patel V, Rassam SM (1995) Role of blood flow and impaired autoregulation in the pathogenesis of diabetic retinopathy. Diabetes 44: 603-607

59. Pang I-H, Yorio T (1997) Ocular actions of endothelins. Proc Soc Exp Biol Med 215: 21-34

60. De la Rubia G, Oliver FJ, Inoguchi T, King GL (1992) Induction of resistance to endothelin-1's biochemical actions by elevated glucose levels in retinal pericytes. Diabetes 41: 1533-1539

61. Chakravarthy U, McGinty A, McKillop J, Anderson P, Archer DB, Trimble ER (1994) Altered endothelin-1 induced contraction and second messenger generation in bovine retinal microvascular pericytes cultured in high glucose medium. Diabetologia 37: 36-42

62. Bursell SE, Clermont AC, Oren B, King GL (1995) The in vivo effect of endothelins on retinal circulation in nondiabetic and diabetic rats. Invest Ophthalmol Vis Sci 36: 596-607

63. Takagi C, Bursell SE, Lin YW et al. (1996) Regulation of retinal haemodynamics in diabetic rats by increased expression and action of endothelin-1. Invest Ophthalmol Vis Sci 37: 2504-2518

64. Ogata M, Naruse M, Iwasaki N et al. (1998) Immunoreactive endothelin levels in the vitreous fluid are decreased in diabetic patients with proliferative retinopathy. J Cardiovasc Pharmacol 31[Suppl 1]:S378-S379

65. Kawamura M, Ohgawara H, Naruse M et al. (1992) Increased plasma endothelin in NIDDM patients with retinopathy. Diabetes Care 15: 1396-1397

66. Laurenti O, Vingolo EM, Desideri GB et al. (1997) Increased levels of plasma endothelin-1 in on-insulin dependent diabetic patients with retinopathy but without other diabetes related organ damage. Exp Clin Endocrinol Diabetes 105[Suppl 2]:40-42

67. Kohan DE (1991) Endothelins in the normal and diseased kidney. Am J Kidney Dis 29: 2-26

68. Morabito E, Corsico N, Serafini S, Martelli EA (1994) Elevated urinary excretion of endothelins in streptozotocin diabetic rats. Life Sci 54:PL197-PL200
69. Turner NC, Morgan PJ, Haynes AC et al. (1997) Elevated renal endothelin-1 clearance and mRNA levels associated with albuminuria and nephropathy in non-insulin dependent diabetes mellitus: studies in obese fa/fa Zucker rats. Clin Sci (Colch) 93: 565-571

70. Shin SJ, Lee YJ, Lin SR, Tan MS, Lai YH, Tsai JH (1995) Decrease of renal endothelin-1 content and gene expression in diabetic rats with moderate hyperglycaemia. Nephron 70: 486-493

71. Vesci L, Mattera GG, Tobia P, Corsico N, Calvani M (1995) Cardiac and renal endothelin-1 binding sites in streptozotocin induced diabetic rats. Pharmacol Res 32: 363-367

72. Fukui M, Nakamura T, Ebihara I et al. (1993) Gene expression for endothelins and their receptors in glomeruli of diabetic rats. J Lab Clin Med 122: 149-156

73. Nakamura I, Saito M, Fukumoto Y et al. (1997) Experimental diabetes upregulates the expression of ureteral endothelin receptors. Peptides 18: 1091-1093

74. Nakamura T, Ebihara I, Fukui M, Tomino Y, Koide H (1995) Effect of a specific endothelin receptor A antagonist on mRNA levels for extracellular matrix components and growth factors in diabetic glomeruli. Diabetes 44 :895-899

75. Hocher B, Lun A, Priem F, Neumayer HH, Raschack M (1998) Renal endothelin system in diabetes: comparison of angiotensin converting enzyme inhibition and endothelin-A antagonism. J Cardiovasc Pharmacol 31[Suppl 1]:S492-S495

76. Benigni A, Colosio V, Brena C et al. (1998) Unselective inhibition of endothelin receptors reduces renal dysfunction in experimental diabetes. Diabetes 47: 450-456

77. Lee YJ, Shin SJ, Tsai JH (1994) Increased urinary endothelin-1 like immunoreactivity in NIDDM patients with albuminuria. Diabetes Care 17: 263-266

78. De Mattia G, Cassone-Faldetta M, Bellini C et al. (1998) Role of plasma and urinary endothelin-1 in early diabetic and hypertensive nephropathy. Am J Hypertens 11: 983-988

79. Blauw GJ, Westendorp RG, Srivistava N et al. (1995) Hypoxia induced arterial endothelin does not influence peripheral vascular tone. J Cardiovasc Pharmacol 26[Suppl 3]:S242-S243

80. Liu J, Chen R, Casley DJ, Nayler WN (1990) Ischemia and reperfusion increase 125I-labeled endothelin-1 binding in rat cardiac membranes. Am $\mathrm{J}$ Physiol 258:H829-H835

81. Douglas SA, James S, Hiley CR (1991) Endothelial modulation and changes in endothelin pressor activity during hypoxia in the rat isolated perfused mesenteric arterial bed. Br J Pharmacol 103: 1441-1448

82. Omland T, Lie RT, Aakvaag A, Arsland T, Dickstein K (1994) Plasma endothelin determination as a prognostic indicator of 1-year mortality after acute myocardial infarction. Circulation 89: 1573-1579

83. Benigni A, Remuzzi G (1999) Endothelin antagonists. Lancet 353: 133-138

84. Williamson JR, Chang K, Frangos M et al. (1992) Hyperglycemic pseudohypoxia and diabetic complications. Diabetes 42: 801-813

85. Tahiliani AG, McNeill JH (1986) Diabetes induced abnormalities in the myocardium. Life Sci 38: 959-974

86. Mankovsky BN, Metzger BE, Molitch ME, Biller J (1996) Cerebrovascular disorders in patients with diabetes mellitus. J Diabetes Complications 10: 228-242

87. Yamauchi T, Ohnaka K, Takayanagi R, Umeda F, Nawata H (1990) Enhanced secretion of endothelin-1 by elevated glucose levels from cultured bovine aortic endothelial cells. FEBS Lett 267: 16-18 
88. Hattori Y, Kasai K, Nakamura T, Emoto T, Shimoda S-I (1991) Effect of glucose and insulin on immunoreactive endothelin-1 release from cultured porcine aortic endothelial cells. Metabolism 40: $165-169$

89. Metsarrine K, Saijonmaa O, Yki-Jarvinen H, Fyhrquist F (1994) Insulin increases the release of endothelin in endothelial cell cultures in vitro but not in vivo. Metabolism 43: 878-882

90. Baumgartner-Parzer S, Wagner O, Waldhäusl W, Roth T, Lorenzi M (1996) Failure of high ambient glucose to affect endothelin-1 synthesis or release by cultured human endothelial cells. Horm Metab Res 28: 610-612

91. Sandirasegarane L, Herman RJ, Gopalakrishnan V (1994) High glucose attenuates peptide agonist-evoked increases in cytosolic free $[\mathrm{Ca} 2+]$ in rat aortic smooth muscle cells. Diabetes 43: 1033-1040

92. Oliver FJ, de la Rubia G, Feener EP et al. (1991) Stimulation of endothelin-1 gene expression by insulin in endothelial cells. J Biol Chem 266: 23251-23256

93. Ferri C, Pittoni V, Piccoli A et al. (1995) Insulin stimulates endothelin-1 secretion from human endothelial cells and modulates its circulating levels in vivo. J Clin Endocrinol Metab 80: 829-835

94. Anfossi G, Cavalot F, Massucco P et al. (1993) Insulin influences immunoreactive endothelin release by human vascular smooth muscle cells. Metabolism 42: 1081-1083

95. Piatti PM, Monti LD, Conti M et al. (1996) Hypertriglyceridemia and hyperinsulinaemia are potent inducers of endothelin-1 release in humans. Diabetes 45: 316-321

96. Juan CC, Fang VS, Hsu YP et al. (1998) Overexpression of vascular endothelin- 1 and endothelin-A receptors in fructose induced hypertensive rat model. J Hypertens 16: $1775-1782$

97. Dick GM, Sturek M (1996) Effects of a physiological insulin concentration on the endothelin sensitive $\mathrm{Ca}^{2+}$ store in porcine coronary artery smooth muscle. Diabetes 45 : $876-880$

98. Hasdai D, Holmes DR Jr, Richardson DM, Izhar U, Lerman A (1998) Insulin and IGF-1 attenuate the coronary vasoconstrictor effects of endothelin-1 but not sarafotoxin 6c. Cardiovasc Res 39: 644-650

99. Nava P, Collados MT, Masso F, Guarner V (1997) Endothelin mediation of insulin and glucose induced changes in vascular contractility. Hypertension 30: 825-829

100. Ramirez LC, Arauz-Pacheco C, Lackner C, Albright G, Adams BV, Raskin P (1992) Lipoprotein (a) levels in diabetes mellitus: relationship to metabolic control. Ann Intern Med 117: 42-47

101. Boulanger CM, Tanner FC, Bea ML, Hahn AW, Werner A, Luscher TF (1992) Oxidized low density lipoproteins induce mRNA expression and release of endothelin from human and porcine endothelium. Circ Res 70: 1191-1197
102. Horio T, Kohno M, Yasunari K et al. (1993) Stimulation of endothelin-1 release by low density and very low density lipoproteins in cultured human endothelial cells. Atherosclerosis 101: 185-190

103. Uyama H, Haraoka S, Shimokama T, Goto K, Dohi K, Watanabe T (1996) Diet induced hypercholesterolemia increases endothelin-1 release by aortic endothelial cells. Pathobiology 64: 328-332

104. Lerman A, Webster MW, Chesebro JH et al. (1993) Circulating and tissue endothelin immunoreactivity in hypercholesterolemic pigs. Circulation 88: 2923-2928

105. Mangiafico RA, Malatino LS, Santonocito M, Spada RS, Polizzi G, Tamburino G (1996) Raised plasma endothelin-1 concentrations in patients with primary hypercholesterolemia without evidence of atherosclerosis. Int Angiol 15: 240-244

106. Merkel LA, Bilder GE (1992) Modulation of vascular reactivity by vasoactive peptides in aortic rings from hypercholesterolemic rabbits. Eur J Pharmacol 222: 175-179

107. Mathew V, Cannan CR, Miller V et al. (1997) Enhanced endothelin mediated coronary vasoconstriction and attenuated basal nitric oxide activity in experimental hypercholesterolemia. Circulation 96: 1930-1936

108. Wascher TC, Toplak H, Krejs GJ, Simecek S, Kukovetz WR, Graier WF (1994) Intracellular mechanisms involved in D-glucose mediated amplification of agonist-induced $\mathrm{Ca} 2$ + response and EDRF formation in vascular endothelial cells. Diabetes 43: 984-991

109. Pieper G (1998) Review of alterations in endothelial nitric oxide production in diabetes. Hypertension 31: 1047-1060

110. Bucala R, Tracey KJ, Cerami A (1991) Advanced glycosylation products quench nitric oxide and mediate defective endothelium-dependent vasodilatation in experimental diabetes. J Clin Invest 87: 432-438

111. Chang KC, Chung SY, Chong WS et al. (1993) Possible superoxide radical induced alteration of vascular reactivity in aortas from streptozotocin-treated rats. J Pharmacol Exp Ther 266: 992-1000

112. Pieper GM (1999) Enhanced, unaltered and impaired nitric oxide-mediated endothelium-dependent relaxation in experimental diabetes mellitus: importance of disease duration. Diabetologia 42: 204-213

113. Boulanger C, Luscher TF (1990) Release of endothelin from the porcine aorta. Inhibition by endothelium-derived nitric oxide. J Clin Invest 85: 587-590

114. Vermes I, Spooren PF, Kalsbeek-Batenburg EM, Haanen C (1993) In addition to von Willebrand factor and urinary albumin excretion, plasma endothelin is an indicator of endothelial dysfunction in diabetes mellitus. Diabetologia 36: $472-473$ 